\title{
Cognitive Impairment in Patients with Diabetes Mellitus on Insulin Therapy
}

\author{
ESAM S. DARWISH, M.D.*; ANWAR M. ALI, M.D.*; WALAA A. MOHAMED, M.D.** and \\ MOHAMED A. ZAKI, M.Sc.* \\ The Departments of Neuropsychiatry* and Internal Medicine**, Assuit University Hospital, Assuit, Egypt
}

\begin{abstract}
Background: Diabetes afflicts almost 382 million individuals around the world and a 592 million expected to be affected by the year 2035, despite the fact that the pathophysiology of cognitive dysfunction in T2DM is hazy, hyperglycemia, hypoglycemia and insulin resistance have significant roles.

Aim of the Study: The aim of the study was to: Evaluate the affection of cognitive function in patients with T2DM on insulin and comparing between the effect of controlled and non-controlled levels of $\mathrm{HbA1C}$ on cognitive function regarding duration of diabetes, duration of insulin therapy, age, sex, level of education and type of occupations of the patients.
\end{abstract}

Patients and Methods: A total of 100 patients diagnosed as T2DM for more than 5 years were included in this study, divided into two groups based on level of HbAlc: Controlled group (50 patients with $\mathrm{HbA} 1 \mathrm{c}$ was $<6.5 \%$ ) and Uncontrolled group (50 patients with $\mathrm{HbA} 1 \mathrm{c}$ was >-6.5) ages of patients was between 35 and 55 years. Each patient was assessed by clinical assessment, laboratory investigations and neuropsychological assessment of cognition by: MMSE and MoCA.

Results: The frequency of cognitive impairment in young adult patients with T2DM was $18 \%$. There were weak negative relationship between age of the patients and the cognitive function, moderately negative relationship between the duration of T2DM and cognitive function, moderate negative relationship between the HbA1C level and the cognitive function and the frequency of cognitive impairment was increasing with increasing level of HbAlc.

Conclusion: Cognitive function in patients with T2DM affected by control of diabetes, duration of T2DM and to less extend age of the patients, and every one of them is an independent risk factor for cognitive impairment.

Key Words: Cognitive impairment - MMSE - MoCA-Duration of diabetes - Glycosylated hemoglobin - Level of education - Type 2 diabetes mellitus (T2DM).

\section{Introduction}

TYPE 2 diabetes mellitus (T2DM) is a common metabolic disease, it is characterized by hypergly-

Correspondence to: Dr. Mohamed A. Zaki, E-Mail: mazamr89@gmail.com cemia, caused by insulin resistance and an inadequate compensation in the secretion of insulin. In the last 5 decades it has become increasingly evident that diabetes may also affect the central nervous system, a complication referred to as 'diabetic encephalopathy', this complication is reflected in impaired cognitive functioning and is also associated with an increased risk of dementia [1,2].

Cognitive functioning is comprised of multiple cognitive domains, such as memory, informationprocessing speed, language, vasoconstriction, perception, attention and executive functions, which can be impaired selectively [3] .

Hyperglycemia in diabetes is due to the insufficient action of insulin, and cognitive impairment is not only closely associated with hyperglycemia, but also with the action of insulin. Insulin enters the brain through the blood-brain barrier where it binds with insulin receptors. In the brain, insulin is involved in various cognitive functions. There is a particularly large number of insulin receptors in the hippocampus and cerebral cortex, which play a central role in memory. Insulin induces the release of $\beta$-amyloid peptide $(A \beta)$ in cells to the cell exterior, and also promotes the expression of insulin degrading enzyme (IDE). As IDE also degrades $A \beta$, if there is lack of insulin, $A \beta$ will accumulate [4]

In the case of hyperinsulinemia or insulin resistance, due to down regulation, there is a decrease in insulin receptors and less insulin comes into the brain. Also, as insulin is degraded by IDE, in the high insulin state, IDE is consumed and its amount

\section{Abbreviations:}

MMSE: Mini Mental State Examination.

MoCA : Montreal Cognitive Assessment scale. 
decreases, resulting in an increase in $\mathrm{A} / 3$ causing cognitive impairment to progress [5]. Also autopsy findings showed that hyperinsulinemia and hyperglycemia as a result of insulin resistance enhanced neurotic plaque formation [6]. In addition, the intranasal administration of insulin has been shown to be effective when its action in the brain is insufficient, and there are expectations that this could become a new type of therapy [7].

\section{Patients and Methods}

This study was a cross sectional and singlearm assessment study of cognitive function in patients with T2DM on insulin. Patient enrollment was between March 2016 and March 2017. Adult T2DM patients (between the ages of 35 and 55 years for more than 5 years) at outpatient diabetes clinic, department of Internal Medicine, Assiut University Hospital.

50 patients with T2DM on insulin with controlled $\mathrm{HbA} 1 \mathrm{c}$ on treatment $(\mathrm{HbA} 1 \mathrm{c}<6.5)$ were included in the study. Another age and sex matched group (50 patients) with T2DM on insulin with uncontrolled blood glucose level (HbA1c > 6.5) with same duration of treatment had the same work up as the first group.

All patients received a description of the study and they were informed about the purpose, risks, benefits and required follow-up. Informed consent was obtained from each participating patient.

The inclusion criteria were:

1- Patients with T2DM.

2- On in insulin therapy for more than 5 years.

3- Aged: 35-55 years.

4- Normal neurological examination with no evidence of central nervous system affection.

5- Educated to high school or above.

\section{The exclusion criteria ruled out:}

1- Patients with hypertension and advanced cardiac condition.

2- Patients with T2DM on oral hypoglycemic drugs and patients with T1DM.

3- Patients aging less than 35 years or more than 55 years.

4- Patients with abnormal neurological examination suggestive of CNS affection or with history of neurological or psychiatric conditions affecting cognition, e.g. (Dementia, Parkinsonism, MS... etc.).
5- Patients with other medical conditions that may affect cognition (uremic, hepatic, thyroid dysfunction, malignancy, vitamin B 12 deficiency, lung diseases, Rheumatological disorder etc.).

6- Patients with visual or hearing impairment, which may interfere with scales application with the patients.

7- Patients receiving drugs that may affect cognition e.g. benzodiazepines, opiates, antidepressants and anticonvulsants.

8- Educated patients below high school or illiterate patients.

Each patient assessed with the following:

A- Clinical assessment includes:

I- Proper history taking \& Full general examination:

Including following data for each patient: age, gender, marital state, highest education level, duration of T2DM, associated medical condition, currently control or not on insulin treatment, blood pressure $(\mathrm{mmHg})$.

\section{II- Full neurological examination:}

According to the sheet of Neurology department, Assiut University hospital, to exclude any neurological disorder.

B-Laboratory investigation:

I- Glycosylated Hemoglobin (HBAl c):

Patients with T2DM, HbA1c of $48 \mathrm{mmol} / \mathrm{mol}$ (6.5\%) was recommended as the cut off point for diagnosing controlled and non-controlled patients in this study.

\section{II- Total lipid profile:}

Including HDL, LDL, triglycerides and total cholesterol, to exclude patients with hyperlipidemia which is a possible cause of cognitive affection.

C- Neuropsychological assessment of Cognitive function:

Every patient assessed once by the established assessment tools which are questionnaire-based scales.

I- Mini Mental State Examination (MMSE) or Folstein test is the most commonly used instrument for screening cognitive function [8]. It is also used to estimate the severity and progression of cognitive impairment and to follow the course of cognitive changes in an individual over time. The maximum score is 30 , a score of 20 to 25 is indicative of mild cognitive impairment [9]. 
II- Montreal Cognitive Assessment scale (MoCA):

MoCA was developed as a tool to screen patients who present with mild cognitive complaints and usually perform in the normal range on the MMSE [10], it is a one-page 30-point test administered in approximately 10 minutes.

The MoCA assesses several cognitive domains. The short-term memory recall and delayed recall, visuospatial abilities, multiple aspects of executive functions, a phonemic fluency task, verbal abstraction, attention, concentration, working memory, Language and Finally, orientation to time and place is evaluated [11].

\section{Statistical analysis:}

We entered the patient data in a Microsoft Excel (2010, Redmond) spreadsheet, data was collected and analyzed using SPSS (Statistical Package for the Social Science, version 20, IBM, and Armonk, New York). Continuous data was expressed in form of mean \pm SD while nominal data was ęxpressed in form of frequency (percentage). Chi ${ }^{2}$-test was used to compare the nominal data of different groups in the study while student $t$-test was used to compare mean of different two groups. Multivariate regression analysis was used to determine the independent risk factors for cognitive impairment in the study.

\section{Ethical Consideration:}

The present study was approved by ethics committee of Faculty of Medicine, Assiut University. All patients received a description of the study and they were informed about the purpose, risks, benefits, alternatives, and required follow-ups. Informed consent was obtained from each participating patient. Confidentiality was assured for all patients.

\section{Results}

The study included 100 patients known to have type 2 diabetes mellitus on insulin therapy divided into two groups based on level of HbAlc:

- Controlled group; patients with HbA $1 \mathrm{c}$ was $<6.5 \%$.

- Uncontrolled group; patients with HbA1c was $>6.5 \%$.

\footnotetext{
Demographic characteristics of the studied patients:

Current study showed that no significant differences between those patients with controlled DM and those with uncontrolled DM where $p$ was $>0.05$.
}

Cognitive assessment of all studied patients: to assess the cognitive function in both groups we use MMSE and MoCA.

\section{Definition of cognitive impairment in the study:}

Cognitive impairment was considered if the patient who had MMSE scores below 25 or MoCA score below 26.

\section{Frequency of cognitive impairment in this study:}

We found that $18(18 \%)$ patients had cognitive impairment (all of those patients had MMSE score $<25$ and MoCA score <26). Fourteen (28\%) patients from those with cognitive impairment had uncontrolled DM while the other four (8\%) patients had controlled DM.

\section{Parameters of MoCA and MMSE in the study:}

- Mo CA: It was noticed that 14 (28\%) patients with uncontrolled DM vs. $4(8 \%)$ patients with controlled DM had cognitive impairment based on MoCA (score <26) with significant difference between both groups $(p=0.01)$. Regarding MoCA; patients with controlled DM had significantly higher score of executive function, language fluency, attention and recalling with $p$-value $<0.05$. Other parameters as naming, orientation, abstraction and language repetition had no significant differences between both groups with $p>0.05$. Also, total score of MoCA was significantly higher in patients with controlled DM ( 27.5 vs. $25.5 ; p=0.00)$.

- MMSE: The study showed that 14 (28\%) patients with uncontrolled DM vs. $4(8 \%)$ patients with controlled DM had cognitive impairment based on MMSE (score <25) with significant difference between both groups $(p=0.03)$. Regarding MMSE, it was noticed that recall and language were significantly different between both groups with higher scores in those with controlled DM with $p$-value was 0.00 for each. It was noticed that the total score of Mini-mental state had no statistical differences between both groups ( $p>0.05$ ).

Demographic characteristics of patients with normal cognitive function vs. those with cognitive impairment:

Regarding the demographic data of the patients according to cognitive function; patients with impaired cognitive function had significant higher duration of DM and age with $p$ was 0.00 for each of them. Majority of - 70 (93.3\%-patients with normal cognitive function had university education or above while only $10(40 \%)$ patients from those with impaired function had university level or above $(p=0.00)$. Also, majority of patients- 45 $(54.8 \%)$ patients with normal cognitive function 
had mentally dependent function and most of those with impaired cognitive function had hand dependent function $(p=0.01)$. Sex, and marital status had no significant differences between both groups where $p>0.05$.

Parameters of MoCA and MMSE in the study according to cognitive function:

- MoCA: Total score was significantly higher in those with normal cognitive function (28.47 vs. $20.5 ; p=0.00)$. Executive function, language fluency, abstraction and recalling were significantly higher in those with normal cognitive function $(p>0.05)$ while other parameters had no significant differences between both groups ( $p>0.05$ ).

- MMSE: Total score was significantly higher in those with normal cognitive function (28.53 vs. $24.02 ; p=0.00)$. Those patients with normal cognitive function had significantly higher orientation, registration and recall scores $(p<0.05)$ while language and attention had no significant differences between both groups $(p>0.05)$.

Correlation between cognitive scores with different parameters in the study:

- Age of patients:

Had significant negative weak correlation with MoCA $[-0.3(0.00)]$ and had significant negative weak correlation with MMSE [-0.33 (0.00)].

\section{- Duration of T2DM:}

Duration of diabetes also had significant negative moderate correlation with MoCA [-0.41 (0.00)] and had significant negative moderate correlation with MMSE [-0.55 (0.00)].

- HbAlc:

HbA $1 \mathrm{c}$ also had significant negative moderate correlation with Montreal Cognitive scale [ -0.6 $(0.00)]$ and had significant negative moderate correlation with MMSE [-0.55 (0.00)].

\section{Type of occupation and cognition:}

It was found that patients with mentally dependent occupation had significantly higher scores of MoCA and MMSE $(p<0.05)$.

Level of HbAlc and cognition in patients with uncontrolled DM:

Based on $\mathrm{HbA} 1 \mathrm{c}$ level in patients with uncontrolled DM it was shown that frequency of cognitive impairment was increasing with increasing level of $\mathrm{HbA1c}$.

Multivariate regression analysis for prediction of cognition impairment in patients with type 2 DM: It was noticed that age of the patients $(>55$ years), uncontrolled DM, duration of DM ( $>10$ years), and level of $\mathrm{HbA} 1 \mathrm{c}(>7.5 \%)$ were independent risk factors for cognition impairment in the current study.

Table (1): Demographic characteristics of studied patients.

\begin{tabular}{llcc}
\hline & $\begin{array}{c}\text { Controlled group } \\
(\mathrm{n}=50)\end{array}$ & $\begin{array}{c}\text { Uncontrolled group } \\
(\mathrm{n}=50)\end{array}$ & $p$-value \\
\hline Age (years): & $52.46 \pm 5.77$ & $54.46 \pm 10.07$ & 0.94 \\
$35-45$ & $23(46)$ & $25(50)$ & \\
$>45$ & $27(54)$ & $25(50)$ & 0.99 \\
Sex: & & & \\
$\quad$ Male & $32(64)$ & $31(62)$ & 0.04 \\
Female & $18(36)$ & $19(38)$ & \\
Education level: & & $32(64)$ & 0.53 \\
$\quad$ University level and above & $43(86)$ & $18(36)$ & \\
$\quad$ Below university level & $7(14)$ & & 0.11 \\
Marital status: & & $45(90)$ & \\
$\quad$ Married & $45(90)$ & $5(10)$ & 0.06 \\
$\quad$ Single & $5(10)$ & $14.23 \pm 3.09$ & \\
Duration of DM (years) & $13.11 \pm 2.98$ & $23(46)$ & \\
Type of occupation: & & $27(54)$ & \\
$\quad$ Mental function & $26(52)$ & & \\
Hand dependent & $24(48)$ & & \\
\hline
\end{tabular}

Continuous data was expressed in for of mean \pm SD while nominal data in form of frequency (percentage). $p$-value was significant if $<0.05$. $\mathrm{n}$ : Number. 
Table (2): Cognitive assessment of both groups.

\begin{tabular}{llcl}
\hline Parameters & $\begin{array}{c}\text { Controlled group } \\
(\mathrm{n}=50)\end{array}$ & $\begin{array}{c}\text { Uncontrolled group } \\
(\mathrm{n}=50)\end{array}$ & $p$-value \\
\hline$M o C A$ : & & & \\
Executive function & $4.4 \pm 0.92$ & $3.8 \pm 1.26$ & 0.00 \\
Naming & $3 \pm 0.00$ & $2.8 \pm 0.41$ & 0.07 \\
Attention & $5.5 \pm 0.51$ & $3.30 \pm 0.87$ & 0.04 \\
Repeation & $2 \pm 0.00$ & $2 \pm 0.00$ & 0.32 \\
Fluency & $0.6 \pm 0.11$ & $0.5 \pm 0.11$ & 0.00 \\
Abstraction & $5.3 \pm 0.87$ & $4.8 \pm 0.94$ & 0.87 \\
Recalling & $4.30 \pm 0.67$ & $1.7 \pm 0.46$ & 0.00 \\
Orientation & $5.9 \pm 0.33$ & $5.1 \pm 0.86$ & 0.98 \\
Total score & $27.5 \pm 2.65$ & $25.5 \pm 4.65$ & 0.00 \\
Cognitive impairment $(<26)$ & $4(8)$ & $14(28)$ & 0.01 \\
MMSE: & & & \\
Orientation & $9.8 \pm 1.19$ & $9.8 \pm 1.19$ & 0.11 \\
Registration & $3 \pm 0.00$ & $3 \pm 0.00$ & 0.54 \\
Attention & $4.8 \pm 0.67$ & $4.7 \pm 0.46$ & 0.67 \\
Recall & $2.5 \pm 0.67$ & $2.1 \pm 0.83$ & 0.00 \\
Language & $8.1 \pm 0.95$ & $7.9 \pm 0.71$ & 0.00 \\
Total score & $27.9 \pm 2.36$ & $27 \pm 1.91$ & 0.07 \\
Cognitive impairment $(<25)$ & $4(8)$ & $14(28)$ & 0.03 \\
\hline
\end{tabular}

- Continuous data was expressed in form of mean \pm SD while nominal data in form of frequency (percentage). $p$ was significant if $<0.05 . \mathrm{n}$; number.

Table (3): Demographic characteristics of patients according to cognitive function.

\begin{tabular}{lccc}
\hline & $\begin{array}{c}\text { Normal cognition } \\
(\mathrm{n}=82)\end{array}$ & $\begin{array}{c}\text { Impaired cognition } \\
(\mathrm{n}=18)\end{array}$ & $p$-value \\
\hline Age (years) & $43.88 \pm 4.8$ & $48.48 \pm 3.68$ & 0.00 \\
Sex: & & & 0.17 \\
$\quad$ Male & $53(65)$ & $10(55)$ & \\
$\quad$ Female & $29(35)$ & $8(45)$ & 0.00 \\
Education level: & & & \\
$\quad$ University level and above & $70(85)$ & $10(55)$ & 0.99 \\
$\quad$ Below university level & $12(15)$ & $8(45)$ & \\
Marital status: & & $18(100)$ & 0.00 \\
$\quad$ Married & $65(79.2)$ & 0 & 0.00 \\
$\quad$ Single & $10(20.8)$ & $14.4 \pm 4.45$ & \\
Duration of DM (years) & $10.6 \pm 3.65$ & & 0.01 \\
Diabetic group: & & $4(22)$ & \\
Controlled & $45(54.8)$ & $14(78)$ & \\
Uncontrolled & $37(45.2)$ & $4(22 \%)$ & \\
Type of occupation: & & $14(78 \%)$ & \\
$\quad$ Mental function & $45(54.8)$ & & \\
Hand dependent & $37(45.2)$ & & \\
\hline
\end{tabular}

- Continuous data was expressed in for of mean \pm SD while nominal data in form of frequency (percentage). $p$-value was significant if $<0.05$. $\mathrm{n}$; number. 
Table (4): Domains of cognitive function.

\begin{tabular}{llll}
\hline Parameters & $\begin{array}{c}\text { Normal cognition } \\
(\mathrm{n}=82)\end{array}$ & $\begin{array}{c}\text { Impaired cognition } \\
(\mathrm{n}=18)\end{array}$ & $p$-value \\
\hline MoCA: & & & \\
Executive function & $4.67 \pm 0.47$ & $2.4 \pm 0.82$ & 0.00 \\
Naming & $3 \pm 0.00$ & $2.6 \pm 0.54$ & 0.98 \\
Attention & $5.67 \pm 0.47$ & $4.6 \pm 0.57$ & 0.32 \\
Repeation & $2 \pm 0.00$ & $2 \pm 0.00$ & 0.00 \\
Fluency & $0.37 \pm 0.11$ & 0 & 0.00 \\
Abstraction & $3.8 \pm 0.1 .79$ & $3.47 \pm 0.44$ & 0.00 \\
Recalling & $3.47 \pm 0.67$ & $1.6 \pm 0.54$ & 0.00 \\
Orientation & $5.47 \pm 0.76$ & $3.6 \pm 0.81$ & 0.00 \\
\hline Total score & $28.47 \pm 1.44$ & $20.5 \pm 2.55$ & 0.00 \\
MMSE: & & & 0.09 \\
Orientation & $9.73 \pm 0.44$ & $9.1 \pm 1.5$ & 0.00 \\
Registration & $3 \pm 0.00$ & $3 \pm 0.00$ & 0.91 \\
Attention & $4.8 \pm 0.43$ & $4 \pm 0.64$ & 0.00 \\
Recall & $2.67 \pm 0.47$ & $7.1 \pm 0.43$ & $0.01 \pm 0.61$ \\
\hline Language & $8.33 \pm 0.60$ & $24.02 \pm 1.19$ & \\
\hline Total score & $28.53 \pm 1.09$ & & \\
\hline
\end{tabular}

Data was expressed in form of mean \pm SD. $p$ was significant if $<0.05$. $n$; number.

Table (5): Correlation between cognitive scores with different parameters in the study.

\begin{tabular}{llc}
\hline Variables & MoCA & MMSE \\
\hline Age & $-0.3(0.00)$ & $-0.33(0.00)$ \\
Duration of DM & $-0.41(0.00)$ & $-0.55(0.00)$ \\
HbA1c & $-0.6(0.00)$ & $-0.55(0.00)$ \\
\hline
\end{tabular}

- Data was expressed in form $r$; indicated to strength of association and $(\mathrm{P})$; indicated to significance of correlation and was considered significant if $<0.05$.

DM : Diabetes mellitus.

HbA1c: Glycosylated hemoglobin.

Table (6): Types of occupation and cognition.

\begin{tabular}{|c|c|c|c|c|}
\hline & \multicolumn{2}{|c|}{$\begin{array}{l}\text { Mentally } \\
\text { dependent } \\
\quad(n=49)\end{array}$} & $\begin{array}{c}\text { Hand } \\
\text { dependent } \\
(\mathrm{n}=51)\end{array}$ & $p$-value \\
\hline Montreal assessment & \multicolumn{2}{|c|}{$29.23 \pm 2.78$} & $27.23 \pm 1.08$ & 0.04 \\
\hline Mini-mental state & \multicolumn{2}{|c|}{$28.11 \pm 3.55$} & $25.12 \pm 2.59$ & 0.00 \\
\hline \multicolumn{5}{|c|}{$\begin{array}{l}\text { - Data was expressed in form of mean } \pm \text { SD. } p \text {-value was significant } \\
\text { if }<0.05 \text {. }\end{array}$} \\
\hline \multicolumn{5}{|c|}{$\begin{array}{l}\text { Table (7): Multivariate regression analysis for prediction of } \\
\text { congitive impairment. }\end{array}$} \\
\hline Variables & & $\begin{array}{l}\text { Odd's } \\
\text { ration }\end{array}$ & $\begin{array}{l}95 \% \\
\text { confidence } \\
\text { interval }\end{array}$ & $p$-value \\
\hline \multicolumn{2}{|c|}{ Age of patients $>55$ years } & 1.2 & $2.33-5.67$ & 0.04 \\
\hline \multicolumn{2}{|l|}{ Uncontrolled DM } & 2.33 & $1.56-3.34$ & 0.00 \\
\hline \multicolumn{2}{|c|}{ Duration of $\mathrm{DM}>10$ years } & 2.1 & $4.44-5.06$ & 0.01 \\
\hline \multicolumn{2}{|l|}{$\mathrm{HbA} 1 \mathrm{c}>7.5 \%$} & 1.7 & $1.09-3.04$ & 0.03 \\
\hline
\end{tabular}

$p$ was significant if $<0.05$

DM :Diabetes mellitus.

HbA1c: Glycosylated hemoglobin.

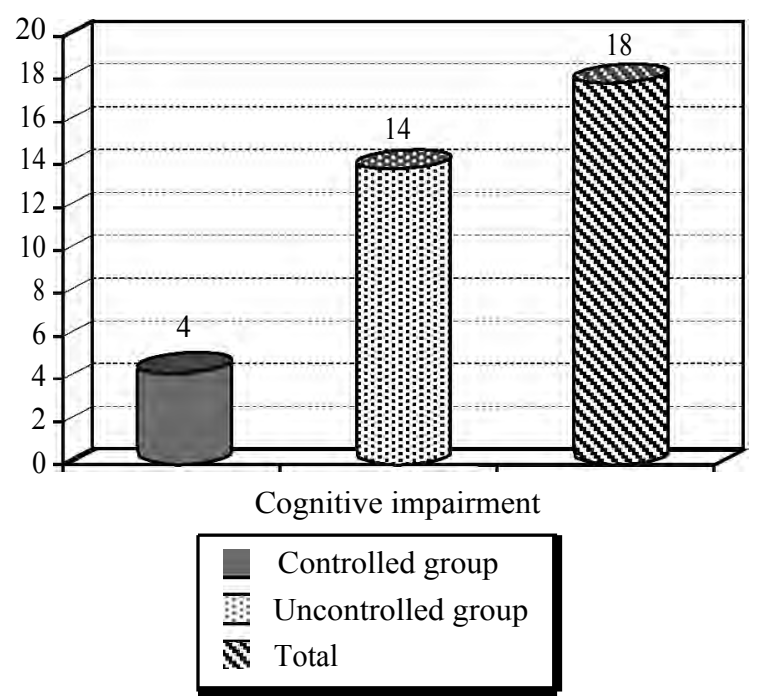

Fig. (1): Frequency of cognitive impairment in the study.

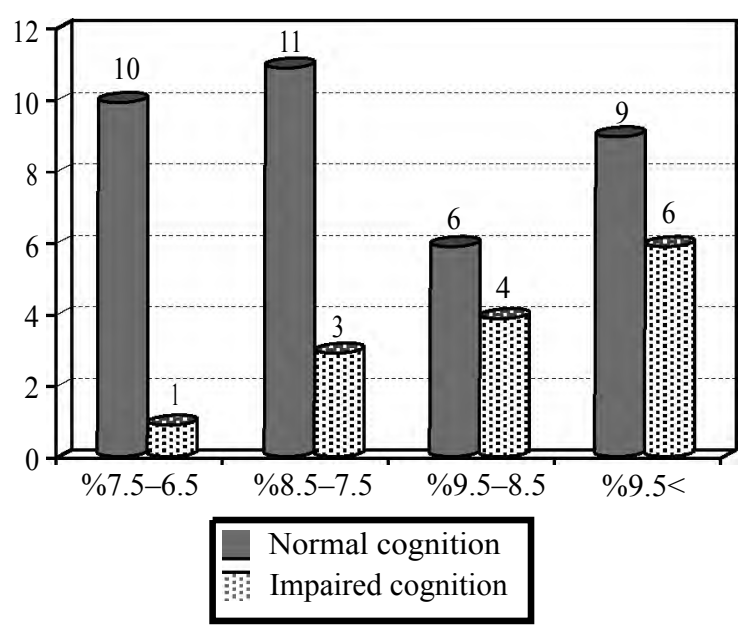

Fig. (2): Frequency of impaired Cognition based on level of $\mathrm{HbA} 1 \mathrm{c}$. 


\section{Discussion}

Our study demonstrated that the prevalence of cognitive impairment between adult patients with T2DM on insulin therapy is $18 \%$.

As regards demographic characteristics of the studied patients:

In our study, the mean age of T2DM patients was $52.9 \pm 6.7$, with male predominance $62 \%$, most of the patients had high educational level (University level and above) $64 \%, 49 \%$ of the patients have mentally dependent occupations and $51 \%$ of the patients have hand dependent occupations $(p>0.05)$.

\section{1- As regard age, age group and cognition:}

We found weak negative relationship between age of the patients with T2DM and the cognitive function and patients with age group between (3545 years) had higher scores of MoCA and MMSE than the other group between ( $45-55$ years) ( $p<$ $0.05)$.

To the opposite of the present study most of studies [12-20], showed a very strong negative relationship between Age and glycosylated hemoglobin level from one side and the cognitive function from the other side. And the present study result stands near the same observation of Roy S, et al., [21].

There are many factors that could explain this difference. First, age-related cognitive impairment is mostly reported after 60 years of age [22], in our study, the mean age of T2DM patients was 52 years, therefore it is appropriate to state that a normal age-related natural decline in the cognitive function after the age of 60 years could have increased the likelihood of a higher prevalence of cognitive impairment in the studies that included older adult T2DM patients.

Second, structural brain imaging studies on T2DM patients over 60 years old show more pronounced micro- and/or macro-vascular complications which do not tend to occur in younger adults [17].

Third, older adult patients tend to have more associated comorbid conditions compared to younger adults, such as hypertension, hyperlipidemia, atherosclerotic cardiovascular disease, depression, etc. These comorbid conditions are independently associated with cognitive decline [9] .

\section{2- As regard duration of diabetes and cognition:}

Our study found a moderately negative relationship between the duration of T2DM and cognitive function scores. More than half of our patients with cognitive impairment had T2DM for more than 10 years. Our findings were similar to the observations of previous studies [21-25], and our study results are different from the results of a study included patients with the mean age 27 years and there was no decline in the cognitive function after an average of 18 years [26]. These findings indicate that factors other than the duration of T2DM must be responsible for adverse influence on cognitive function.

\section{3- As regard educational level and cognition:}

We found that the level of education significantly affect the cognitive function in our young adult T2DM patients as Majority of patients (93.3\%) with normal cognitive function had university education or above while only $10(40 \%)$ patients from those with impaired function had university level or above $(p=0.00)$. Our findings are the same as the findings of studies made by ME. Dupre, et al., [27] and differ from the study that found that the level of education did not significantly affect the cognitive function in young adult T2DM patients [21].

\section{4- As regards type of occupation and cognition:}

In the current study we found that those patients with mentally dependent occupations had significantly higher scores of MoCA and MMSE than patients with hand dependent occupations $(p<0.05)$. Our findings are similar to the observations of previous studies [28-30]

\section{5- As regard HBAl c and cognition:}

We found moderate negative relationship between the $\mathrm{HbA} 1 \mathrm{C}$ level and the cognitive function. Our observation stands markedly different from the observations of the majority of the studies that have shown a very strong negative relationship between glycosylated hemoglobin level and the cognitive function [12-20] and stands near the same observation of a recent study to assess cognitive function and control of T2DM in young adults [27]

\section{6- As regard possible factors associated with cog- nitive impairment in T2DM by multivariate logistic regression models:}

Based on previous statistical conclusions, T2DM (controlled or not), hyperlipidemia (yes or no), age, sex, education, the scores of MMSE and MoCA, were included in the multivariate logistic regression models. We found that uncontrolled 
T2DM, duration of T2DM (>10 years), and level of $\mathrm{HbA} 1 \mathrm{c}(>7.5 \%)$ are independent risk factors for cognition impairment in the current study. And this result is close to the results made in previous studies $[27,31]$.

\section{Conclusion:}

Cognitive dysfunction in patients with T2DM is significantly affected by control of diabetes (level of HbA1c), duration of T2DM, and to less extends to age of the patient, and we can consider each one of them is an independent risk factor for cognitive impairment.

Financial support and sponsorship:

Nil.

\section{Conflicts of interest:}

There are no Conflicts of interest.

\section{Acknowledgement:}

The authors wish to warmly thank Dr. Amal Mohamed Tohamy, Lecturer of Neurology, Assuit University Hospital for her support and suggestion of the idea of that study, and the doctors of Neuropsychiatry department, Assuit University Hospital, Egypt.

\section{References}

1- GISPEN, WILLEM HENDRIK and GEERT-JAN BIESSELS.: "Cognition and synaptic plasticity in diabetes mellitus." Trends in Neurosciences, 23.11: 542-549, 2000.

2- BIESSELS., GEERT JAN, et al.: "Risk of dementia in diabetes mellitus: A systematic review". The Lancet Neurology, 5.1: 64-74, 2006.

3- LEZAK and MURIEL DEUTSCH: Neuropsychological assessment. Oxford University Press, USA, 2004.

4- YOUNG, SARA E. and ARCH G.: Mainous, and Mark Carnemolla. "Hyperinsulinemia and cognitive decline in a middle-aged cohort." Diabetes Care, 29.12: 2688-2693, 2006.

5- MATSUZAKI T., SASAKI K., TANIZAKI Y., et al.: Insulin resistance is associated with the pathology of Alzheimer disease. The Hisayama Study. Neurology, 75: 764-770, 2010.

6- RÖNNENMAA E., ZETHELIUS B., SUNDELÖF J., et al.: Impaired insulin secretion increased the risk of Alzheimer disease. Neurology, 71: 1065-1071

7- SHEMESH E., RUDICH A., HARMAN-BOEHM I., et al.: Effect of intranasal insulin on cognitive function_A systematic review. J. Clin. Endocrinol. Metab., 97: 366376, 2012.

8- L. KURLOWICZ and M. WALLACE: The mini-mental state examination (MMSE) - Journal of gerontological nursing - healio.com, 1999.

9- DONG, YANHONG, et al.: "The Montreal Cognitive Assessment (MoCA) is superior to the Mini-Mental State
Examination (MMSE) for the detection of vascular cognitive impairment after acute stroke". Journal of the Neurological Sciences, 299.1: 15-18, 2010.

10-NASREDDINE, ZIAD S., et al. "The Montreal Cognitive Assessment, MoCA: A brief screening tool for mild cognitive impairment". Journal of the American Geriatrics Society, 53.4: 695-699, 2005.

11- ZIMMET, PAUL Z., et al.: "Diabetes: A 21 st century challenge." The lancet Diabetes \& Endocrinology, 2.1: 56-64, 2014.

12- CUKIERMAN-YAFFE, TALI, et al.: "Relationship between baseline glycemic control and cognitive function in individuals with type 2 diabetes and other cardiovascular risk factors." Diabetes Care, 32.2: 221-226, 2009.

13- YAFFE, KRISTINE, et al.: "Diabetes, glucose control, and 9-year cognitive decline among older adults without dementia." Archives of Neurology, 69.9: 1170-1175, 2012.

14-KAFFASHIAN S., DUGRAVOT A., ELBAZ A, SHIPLEY M.J., SABIA S., KIVIMÄKI M., et al.: Predicting cognitive decline: A dementia risk score vs. the Framingham vascular risk scores. Neurology. 80:1300-6, 2013.

15- RAWLINGS, ANDREEA M., et al.: "Diabetes in Midlife and Cognitive Change Over 20 YearsA Cohort StudyDiabetes in Midlife and Cognitive Change Over 20 Years." Annals of Internal Medicine, 161.11: 785-793, 2014.

16- BIESSELS., GEERT JAN, et al.: "Risk of dementia in diabetes mellitus: a systematic review". The Lancet Neurology, 5.1: 64-74, 2006.

17- CUKIERMAN T., H.C. GERSTEIN, and J.D. WILLIAMSON: "Cognitive decline and dementia in diabetessystematic overview of prospective observational studies". Diabetologia, 48.12: 2460-2469, 2005.

18- Cheng G., Huang C., Deng H. and Wang H.: Diabetes as a risk factor for dementia and mild cognitive impairment: A meta-analysis of longitudinal studies. Intern. Med. J., 42: 484-91, 2012.

19-CRANE P., WALKER R., HUBBARD R.A., LI G., NATHAN D.M., ZHENG H., et al.: Glucose levels and risk of dementia. N. Engl. J. Med., 369: 540-8, 2013.

20- ROY S., KIM N., DESAI A., KOMARAGIRI M., BAXI N., JASSIL N., BLESSINGER M., KHAN M., COLE R., DESAI N. and TERRIGNO R.: Cognitive function and control of type 2 diabetes mellitus in young adults. North American Journal of Medical Sciences. May., 7 (5): 220, 2015.

21- SPAUWEN P.J., KÖHLER S., VERHEY F.R., STEHOUWER C.D. and VAN BOXTEL M.P.: Effects of type 2 diabetes on 12-year cognitive change: Results from the Maastricht Aging Study. Diabetes Care, 36: 1554-61.

22- Langa K.M. and Levine D.A.: The diagnosis and management of mild cognitive impairment: A clinical review. JAMA, 312 : 2551-61, 2014.

23- JACOBSON A.M., MUSEN G., RYAN C.M., SILVERS N., CLEARY P., WABERSKI B., et al.: Diabetes Control and Complications Trial/Epidemiology of Diabetes Interventions and Complications Study Research Group. LongTerm effect of diabetes and its treatment on cognitive function. N. Engl. J. Med., 356: 1842-52, 2007. 
24- DUPRE M.E., SILBERBERG M., WILLIS J.M., FEINGLOS M.N.: Education, glucose control, and mortality risks among U.S. older adults with diabetes. Diabetes Res. Clin. Pract., 107: 392-9, 2015.

25- MENEILLY G.S., CHEUNG E., TESSIER D., YAKURA C., and TUOKKO H.: The effect of improved glycemic control on cognitive functions in the elderly patient with diabetes. J. Gerontol., 48: M117-21, 1993.

26- MAYEDA E.R., HAAN M.N., NEUHAUS J., YAFFE K., KNOPMAN D.S., SHARRETT A.R., et al.: Type 2 diabetes and cognitive decline over 14 years in middle-aged african americans and whites: The ARIC Brain MRI study. Neuroepidemiology, 43: 220-7, 2014.

27- BERKMAN L.F., GLASS T., BRISSETTE I. and SEEMAN T.E.: From social integration to health: Durkheim in the new millennium. Soc. Sci. Med., 51 (6): 843-57, 2000.

28- MIN J.Y., PARK J.B., LEE K.J. and MIN K.B.: The impact of occupational experience on cognitive and physical functional status among older adults in a representative sample of Korean subjects. Annals of occupational and environmental medicine. Mar., 20; 27 (1): 11, 2015.

29- GRACIA REBLED A.C., SANTABÁRBARA SERRANO J., LÓPEZ ANTÓN R., TOMÁS AZNAR C. and MAR COS ARAGÜÉS G.: Occupation and Risk of Cognitive Impairment and Dementia in People in over 55 Years: A Systematic Review, Spain. Revista Española de Salud Pública. 90, 2016.

30- JORM A.F., RODGERS B., HENDERSON A.S., KORTEN A.E., JACOMB P.A., CHRISTENSEN H. and MACKINNON A.: Occupation type as a predictor of cognitive decline and dementia in old age. Age and Ageing. Jul., 1; 27 (4): 477-83, 1998.

31- HERZOG R.I. and SHERWIN R.S.: Diabetes. Can tight glycemic control in diabetes benefit cognition? Nat. Rev. Neurol., 8: 124-6, 2012.

\section{أضطرابات القدرات المعرفية للى المرضى المصابون بداء السكرى

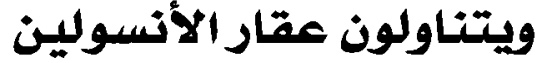

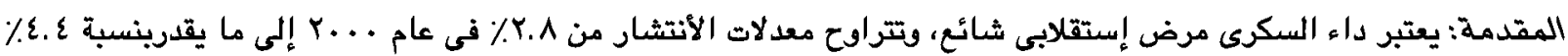

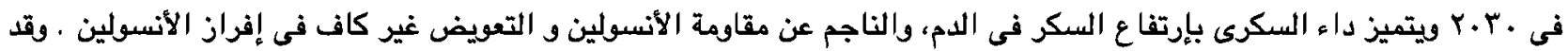

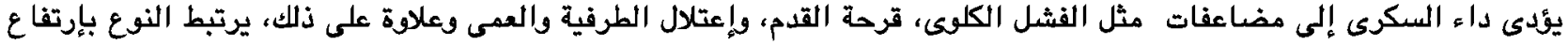

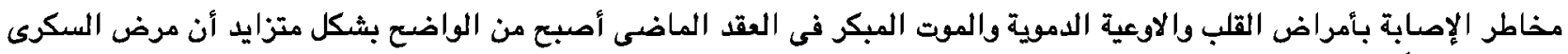

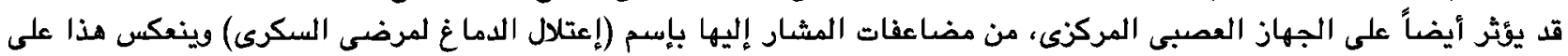

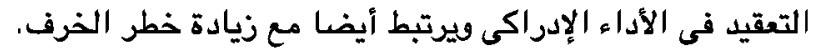

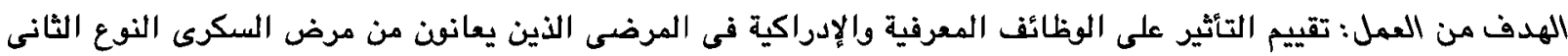

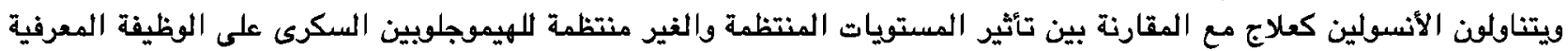
والإدراكية المرضى فيما يتعلق بالعمر والجنس ومدة العلاج الأنسولين ومستوى التعليم ونوع المهنة المرضين.

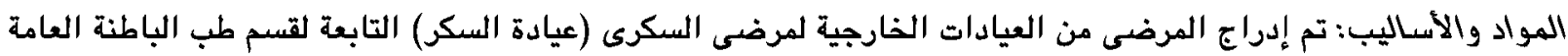

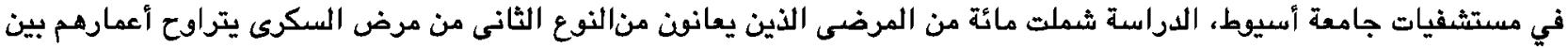

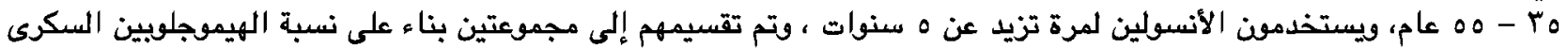

- المجموعة الاولى: خمسين من مرضى السكرى لديهى نسبة منتظمة من الهيموجلوبين السكرى أقل من ه 7 (HBA1c).

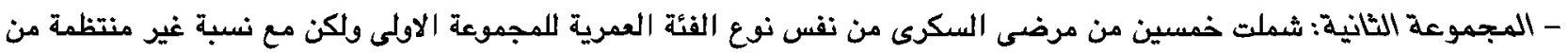

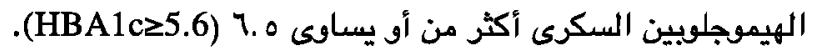

خضعت المجموعتين إلى نفس خطة العمل من حيث التقييم الاكلينيكى وأخذ التاريخ المرضى والفحوصات المعملية والتقييم العصبى والنفسى.

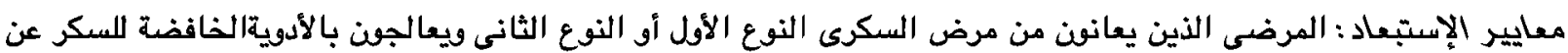

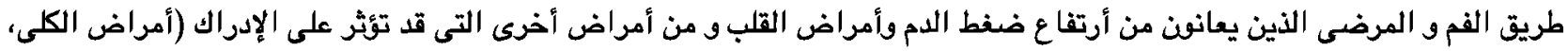

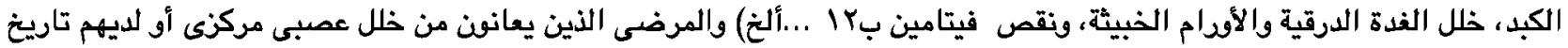

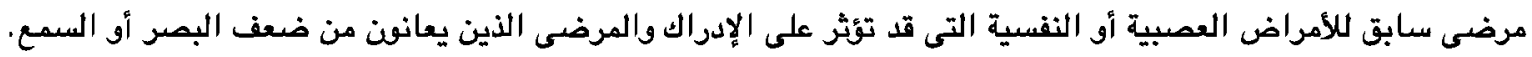




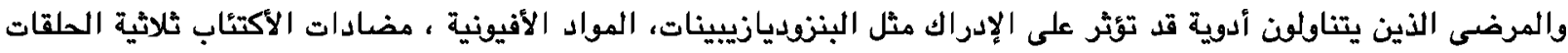

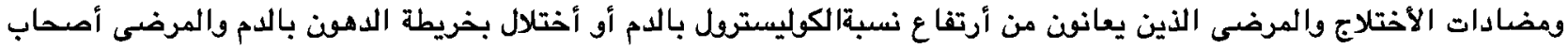
ذوى تعليم أقل من المرحلة|الثانوية.

الأساليب المستخذ مة في البحث: تم تقييم كل المرضى المشاركون فى البحث من المجموعتين بما يلى :

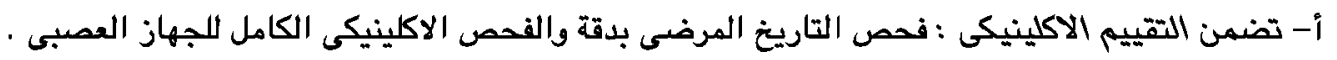

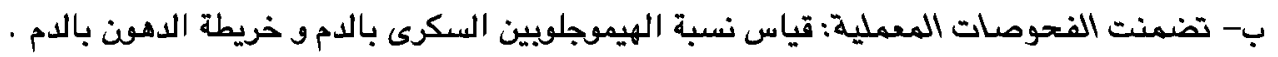

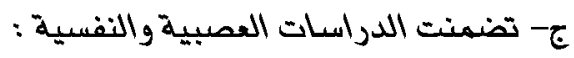

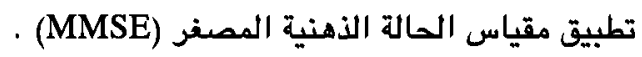

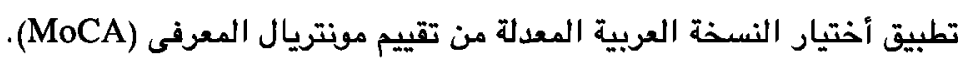
وقد أظهرت النتائج الآتية :

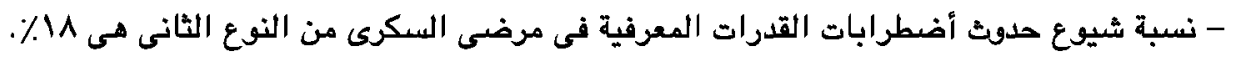

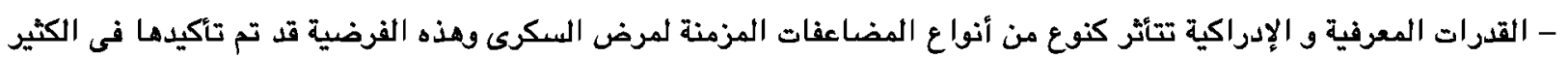

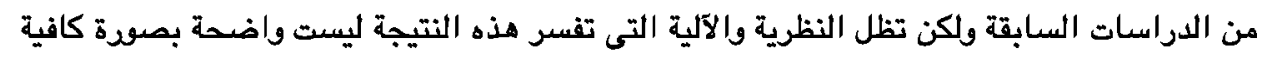

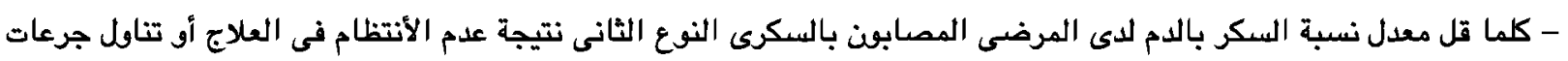

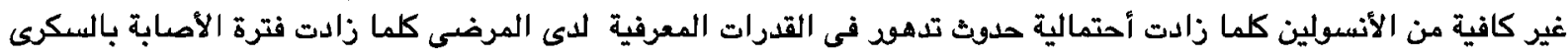

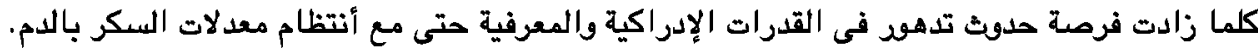

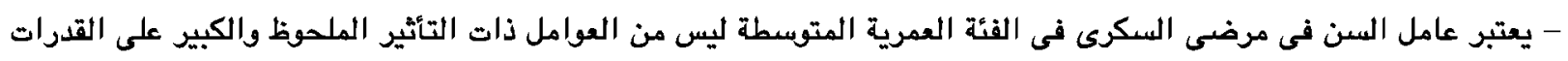
الإدراكية والمعرفية. - كلما أرتفع مستوى تعليم ورظيفة المريض بحيث تعتمد على مستوى المجهوديد العقلى والتفكير بصودة أكبر من أستخدام المجهود

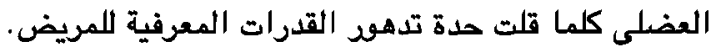

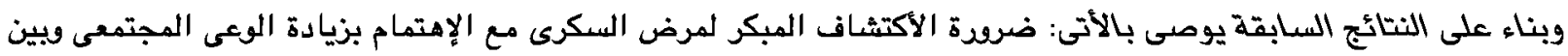

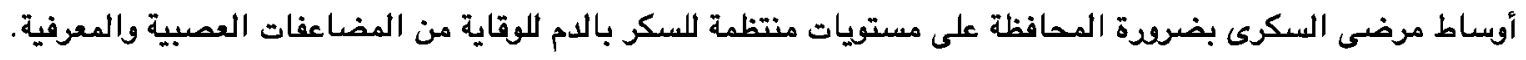

